\title{
New therapeutic targets for ACE inhibitors and angiotensin receptor blockers
}

\author{
Paweł Petkow-Dimitrow \\ Department of Cardiology, Jagiellonian University School of Medicine, Kraków, Poland
}

\begin{abstract}
Angiotensin-converting enzyme inhibitors (ACE-I) and angiotensin receptor blockers (ARB) possess multiple beneficial effects such as cardioprotection, cerebroprotection, nephroprotection which provide opportunity to select the most suitable drug for the target vascular bed (e.g. coronary, or cerebral circulation). In some clinical settings, combined therapy ACE-I with ARB (double blockage of the renin-angiotensin-aldosteron system) may appear the most effective. These drugs (especially ARB) may successfully prevent atrial fibrillation and play a protective role in metabolic syndrome. Recently, it has been demonstrated that losartan is able to inhibit vasodilatation of the aorta in Marfan syndrome, which might prevent sudden death due to aorta rupture. An increasing role of ARB is most beneficial in hipotensive therapy (inhibition/regression of hypertension-related organ damage). With particular interest, results of the ONTARGET study are being awaited. This study is focused on the effect of dual blockade (ramipril and telmisartan) on reduction of the occurrence of myocardial infarction, stroke, and heart failure.
\end{abstract}

Key words: ACE inhibitors, angiotensin, angiotensin receptor blockers

\section{INTRODUCTION}

History of the pharmacotherapy of renin-angiotensin-aldosteron (RAA) axis dates back over a quarter of century. This history had some surprising, but also very beneficial reversals. Angiotensin-converting enzyme inhibitors (ACE-I), drugs originally intended to treat arterial hypertension, turned out to be a key to neurohormonal (readaptive) treatment of congestive heart failure. After it had occurred that the ACE-I are multi-potential and irreplaceable drugs (a milestone in cardiology development), a potential rival appeared - angiotensin II receptor blockers (ARB), which in certain cases act better (e.g., cerebral protection in primary and secondary stroke prevention). Of note, instead of competition, the cooperation between those drugs was achieved - an interesting new trend (gaining an increasing acceptance) of the RAA axis dual blockade by the simultaneous use of the ACE-I and ARB. In some clinical cases this simultaneous (two-level) therapy - a remedy for the "escape from RAA system" - is very useful (nephroprotection). The next success of the RAA blocking drugs is their efficacy in the prevention of atrial fibrillation and treatment of metabolic syndrome. In both diseases of an increasing frequency (as a result of population ageing) especially the ARB are very efficient in prevention.

Correspondence to:

dr hab. med. Paweł Petkow-Dimitrow, II Klinika Kardiologii, Collegium Medicum Uniwersytetu Jagiellońskiego, ul. Kopernika 17, 31-501 Kraków, Poland, phone: +48-12-424-71-70, fax: +48-12-424-71-84, e-mail: dimitrow@mp.pl

Received: May 14, 2007. Accepted in final form: June 14, 2007.

Declared conflict of interest. Author is a consultant of Adamed company.

Pol Arch Med Wewn. 2007; 117 (4): 164-170

Copyright by Medycyna Praktyczna, Kraków 2007

\section{The role of $A R B$ in stroke prevention}

Among the trials concerning hypertensive patients in which the usefulness of the ARB in primary cerebral stroke was assessed, the LIFE [1] and SCOPE [2] are of special interest. In the Losartan Intervention For Endpoint trial (LIFE) reduction in hypertension was observed in the elderly patients suffering from isolated systolic hypertension. After losartan treatment stroke frequency was decreased by $25 \%$ in comparison to atenolol. The similar efficacy was shown by candersartan in the SCOPE trial. The MOSES trial showed that in secondary prevention of stroke eprosartan was successful [3]. Paying attention to the special efficiency of ARB, other hypotensive drugs were analyzed (some of them known as "therapeutic pillars" in treatment of cardiovascular diseases and their complications, e.g. cerebral stroke). A valuable summary of $\beta$-adrenolytics efficacy in stroke prevention, published in Lancet, was made on 6825 patients by Carlberg et al. [4]. Surprisingly, comparing to other hypotensive drugs, atenolol increased by $30 \%$ the risk of stroke. Drugs which decrease the risk of cerebral stroke were suggested to be called "cerebroprotective drugs". Besides thiazide diuretics, the ARB were also included to this group [4]. The high efficacy of the SARB was mentioned above; another important observation is that if instead of the $\mathrm{AT}_{2}$ receptor blockade, the ACE-I are used, the cerebroprotective effect is lost (a complex role of $\mathrm{AT}_{2}$ receptor was described below in detail). For example, in the PROGRESS trial [5] perindopril in monotherapy decreased blood pressure by $5 \mathrm{mmHg}$ and the risk of stroke by $5 \%$ - which was statistically insignificant. Confronted to the Post-stroke Antihypertensive Treatment Study (PATS) [6], the use of indapamide in monotherapy also 
REVIEW ARTICLES

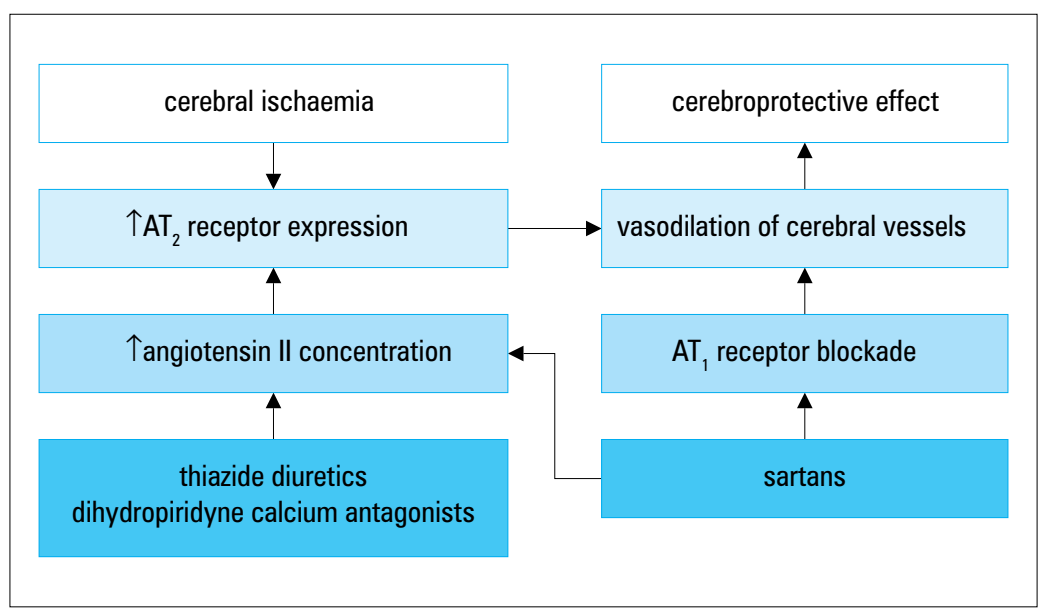

Fig. Cerebroprotection mechanism of selected hypotensive drugs

decreased blood pressure by $5 \mathrm{mmHg}$, but the risk of stroke was much more diminished - by $29 \%$. In the famous Antihypertensive and Lipid-Lowering treatment to prevent the Heart Attack Trial (ALLHAT) [7] there were no differences in the risk of stroke between groups treated with amlodipine and chlortalidone. Lizinopril as a representative of the ACE-I appeared to be less favorable than chlortalidone in Afro-American $(R R=1.40)$ and woman $(R R=1.22)$ subgroups. The above data show different therapeutic effects of the ACE-I and ARB.

Based on these inspiring data, a meta-analysis concerning coronary artery disease and strokes was performed. It was based on 28 trials, comparing calcium channel blockers, diuretics, $\beta$-adrenolytics and a placebo [8]. An impressive total number of 179122 patients was connected with the actual number of 9509 coronary episodes and 5971 strokes. It appeared that the use of the ACE-I in coronary artery disease prevention was more effective than the use of calcium channel blockers, whereas in stroke prevention the effectiveness was inverted. The vascular bed-organ specificity concept was then confirmed retrospectively - cerebroprotection using the ARB and cardioprotection using the ACE-I. To better explain these intriguing relations concerning the organ-selective use of drugs, one has to investigate thoroughly the functional background of the RAA axis. This exploration will also explain why thiazide diuretics and dihydropiridyne calcium antagonists reveal the action similar to the ARB (fig.) $\{9,10]$.

\section{Dual action of the ARB - the role of angiotensin receptor types}

Angiotensin II (ANG II) is the most important element of the RAA axis, since it plays a pivotal role in the development of cardiovascular diseases, both through the hemodynamic and direct influence on vessels, as well as indirectly through aldosterone stimulation [11,12]. The ANG II derives from the ANG I in reaction catalyzed, among others, by the ACE. Through the activation of angiotensin receptors, biolo- gical action of the ANG II is transduced. The basal and the best known is the $\mathrm{AT}_{1}$ receptor, however, several others were also detected ( $\left.\mathrm{AT}_{2}, \mathrm{AT}_{3}, \mathrm{AT}_{4}\right)$; currently, the clinical impact of the $\mathrm{AT}_{2}$ receptor is shown $[13,14]$. By the activation of the $\mathrm{AT}_{1}$ receptor, the ANG II mediates several processes: the release of aldosterone with the consequent retention of sodium and water, increased release of epinephrine and endothelin (neurohormonal effect), vasoconstriction, increased myocardial contractility, cell proliferation and hypertrophy, as well as oxidative and inflammatory action. Recently, the proatherogenic action of the ANG was shown, since the activation of the $\mathrm{AT}_{1}$ receptor causes unfavorable changes of lipid and coagulation parameters, which leads to atherosclerotic plaque development. The effect of the ANG II by the $\mathrm{AT}_{2}$ receptors is partially opposite to the effects mediated by the AT1 receptors - the activation of the $\mathrm{AT}_{2}$ receptors causes vasodilatation and antimitogenic as well as apoptotic rate decreasing actions. However, the role of the $\mathrm{AT}_{2}$ receptors is more complex; in certain cases they send signals similar to the $\mathrm{AT}_{1}$ receptors, causing the expression of the nuclear factor $\kappa \mathrm{B}(\mathrm{NF}-\kappa \mathrm{B})$, which is responsible for inflammatory and fibrotic reactions.

The activation of the $\mathrm{AT}_{2}$ receptors in the circulatory system leads to an increase of nitric oxide, prostaglandin $\mathrm{I}_{2}$ and bradykinin synthesis; it also leads to a decrease in the type $\mathrm{T}$ calcium channels activity and the opening of potassium channels $[13,14]$. The $\mathrm{AT}_{2}$ receptors stimulation causes small vessels vasodilation and recruits collaterals in the ischemic region; it also protects against the consequences of anoxia (by increasing neuronal resistance to oxygen deficiency). In contrast to the $\mathrm{AT}_{2}$ receptors selective recruitment action in ischemic region, bradykinin (increased by the ACE-I) causes vasodilatation also in non-ischemic regions [15]. In consequence, vasodilative competition can occur between ischemic and non-ischemic regions, with the subsequent ischemic region steal syndrome.

The ARB inhibit the RAA axis activity, but the mechanism of action is different from that of the ACE-I. The ACEI decrease the ANG II production, whereas the ARB act by competitive and selective blocking of the ANG II action. It 
was suggested that the $\mathrm{AT}_{1}$ receptor blockade acts in cerebroprotective mode, since it diminishes the vasoconstriction of large cerebral vessels (fig.) and restricts inflammation, connected with ischemic-reperfusion damage [16]. By this receptor blockade seemingly a better inhibition of the RAA axis, than by the ACE-I, was achieved. However, there is a drawback of the $\mathrm{AT}_{1}$ receptor blockade: by the inhibition of the "feedback loop", the ARB cause the increase of the ANG II concentration.

The ACE-I act in another way, since they decrease the ANG II concentration. In a group of patients with a low concentration of the ANG II (e.g., hypertensive Afro-Americans), this difference in clinical effects between the two classes of drugs, as a result of an opposite action on the ANG II concentration, is of a special importance. For example, in the ALLHAT trial the risk of stroke in this population was by $40 \%$ higher in the lizinopril-treated comparing to the chlortalidone (diuretic)-treated group, despite a very similar degree of blood pressure reduction. A question arises why the increase of the ANG II concentration causes cerebroprotection. The increase of the ANG II concentration causes a non-inhibited stimulation of the $\mathrm{AT}_{2}$ receptors - number of which is additionally increased. This phenomenon is called up-regulation.

The $\mathrm{AT}_{2}$ receptor which plays a key role in cerebroprotection is also stimulated by diuretics and dihydropiridyne calcium antagonists (fig.) [9,10]. The direct blockade of the $\mathrm{AT}_{1}$ receptor, caused exceptionally by sartans, influences also cerebral vessel vasodilatation. $\beta$-adrenolytics, dihydropiridyne calcium antagonists and the ACE-I lack this favorable effect.

In the experimental model of stroke - the closure of cervical artery (preceded by drug administration), a decrease of mortality after the ARB, in comparison to the ACE-I was obtained [17]. It was accompanied by a faster partial reflow on the stroke-induced side. The exceptional role of the ARB is confirmed by the observation that in the case of combined administration of the ARB and ACE-I, there was no decrease of mortality detected. Coming from bench to bedside, it was revealed that in patients after cerebral ischemia, the expression of the $\mathrm{AT}_{2}$ receptors is increased (fig.). That is why sartans may occur especially beneficial in secondary stroke prevention.

\section{Dual ACE-I and ARB blockade}

Another novelty in the RAA blockade, after the cerebroprotective effect, is the ACE-I and ARB combined treatment concept [18]. This idea was born on the basis of several observations. The main premise was that no drug used in monotherapy (despite constant improvement of drugs: increased biological availability, extended time of action, improvement of penetration to tissues) is able to block totally the RAA axis. Importantly, the effect of blockade is eminent, since in the peak first action of the ACE-I, the RAA activity is decreased by $60-80 \%$ [18]. However, this submaximal blockade represents only the initial effect of treatment and unfortunately, during the next days of therapy, the RAA activity is unfavo- rably increased. This phenomenon is best known concerning the ACE-I, especially during the treatment of heart failure; it is not stopped despite the maximization of doses [19]. Despite the use of high ACE-I doses, secondary increase of the ANG II concentration is detected, which in heart failure leads to the worse prognosis [20]. This phenomenon is called the "escape from the RAA system" and the breakout of ACE pharmacological inhibition. This phenomenon is mainly due to a possibility of the ACE-independent, alternative pathway of the ANG II generation. It was proved that there are other enzymes beside the ACE, which are able to competitively catalyze the reaction of the ANG I to ANG II conversion, such as chymase, catepsin D and G, tonin and the CAGE (chymostatin-sensitive angiotensin II - generating enzyme). Chymase, both in the myocardium and in the vacular bed, plays a special role [18]. Restriction on the escape from the RAA system phenomenon is possible after joint therapy, inhibiting the activity of this system on two independent levels. Apart from restriction, the ACE-I and sartans association gives extra benefits since the ANG II is a precursor of another peptides - ANG III and IV. From the ANG III by the use of aminopeptidase B, the ANG IV is synthesized. The ANG IV by stimulation its specific receptor the $\mathrm{AT}_{4}$ reveals an unfavorable profibrinogenic activity and increases the PAI-1 activity. Proatherothrombogenic activity, by increasing the LDL cholesterol oxidation, is also shown by the ANG II [21]. On the one hand dual blockade with the ACE-I and the ARB restricts the ANG III and IV synthesis, on the other hand inhibits its action on the $\mathrm{AT}_{1}$ receptor.

Data from experimental research, pointing to benefits from the multilevel blockade of the RAA system are nowadays confirmed in clinical research, concerning hypertensive patients with or without nephropathy (mainly diabetic) [2228] and with heart failure [29-35]. It seems that the ACE-I and ARB dual blockade is able to inhibit the RAA system activity on the tissue level more effectively than monotherapy. For example the intrarenal angiotensin converting enzyme is hardly accessible even for the lipophilic ACE-I, application of which only in a small degree inhibits the local synthesis of the ANG II. Instead, the nephroprotective-acting ARB inhibit effectively the RAA tissue activity by decreasing angiotensinogen expression and inhibiting the ANG II internalization from circulation to tissues. Hypertensive patients revealed the increased the hypotensive effect of dual blockade by the various ACE-I and sartans combinations, in comparison to monotherapy. Special benefits of this therapy concern patients with hypertension and non-insulin dependent diabetes complicated by microalbuminuria [22,23]. Similar advantages may receive hypertensive patients with nephropathy caused by other factors than diabetes $[24,25]$. In the COOPERATIVE trial [26] it was shown for the first time that in patients with non-diabetic nephropathy the dual blockade inhibits renal insufficiency better than every separate drug. A complicated end-point (two-fold increase of creatinine concentration or extreme renal failure) appeared in $11 \%$ of patients treated with 
the dual blockade (losartan and trandolapril), in 23\% treated only with losartan $(\mathrm{p}=0.016)$ and in $23 \%$ administered trandolapril monotherapy ( $\mathrm{p}=0.018$ ).

As regards heart failure, one must realize that in this disease the RAA system activity is augmented and the increased ANG concentration is an unfavorable prognosis factor. The dual blockade decreased the NYHA level and restricted the detrimental myocardial remodelling. In the Val-HeFT trial [29] sartan addition to the previously used ACE-I decreased the occurrence of the complicated end-point risk (death + morbidity due to heart failure). In the CHARM-Added trial [30] the dual blockade decreased a risk of cardiovascular complications. In patients treated with the dual blockade hospitalization due to heart failure was rare $(\mathrm{p}<0.01)$ and death from a cardiovascular cause was also uncommon.

\section{ARB in metabolic syndrome}

Nowadays metabolic syndrome becomes epidemic. It is frequently accompanied by hypertension (one of syndrome's factors) which makes physicians maximize pharmacotherapy. The multidirectional effect of sartans makes them a valuable treatment tool. Discussing the role of sartans in hypertensive patients with metabolic syndrome, it was shown that decreased insulin resistance is a key factor of the special usefulness of these hypotensive drugs. The advantages of sartans, improving metabolic disturbances, are:

1) decrease of insulin resistance, shown in the ICARUS trial [36],

2) agonistic effect of some ARB on PPAR- $\gamma$ receptors which improves insulin sensitivity,

3) neutral effect on carbohydrate and lipid metabolism, documented in several trials including the ALPINE trial [37],

4) demonstration in trials (LIFE with losartan, CHARM and VALUE) a reduction of new non-insulin-dependent diabetes cases,

5) nephroprotective action, e.g. the decrease of microalbuminuria in patients with non-insulin-dependent diabetes.

The ARB demonstrate also other - extrametabolic, equally desired effects: a beneficial effect on regression of left ventricle hypertrophia, a high hypotensive efficiency and an excellent tolerance by patients.

\section{Prevention of atrial fibrillation}

The better and better effectiveness of electrophysiological procedures allows the effective treatment of supraventricular and ventricular causes of cardiac arrhythmias. Unfortunately, the "Achilles' heel" of this invasive method is atrial fibrillation treatment, since these operations are less effective and more expensive. Another disadvantage is the possibility of complications with the subsequent implantation of cardiostimulator. Therefore, pharmacotherapy is the main treatment of atrial fibrillation, however, commonly used classical antiarrhythmic drugs (mainly from class I, II and IV) have a limited efficacy and tolerance, especially during prolonged treatment (which is the usual therapeutic horizon perspective in atrial fibrillation). Due to above restrictions, advisable is a search for new therapeutic modalities increasing efficacy of treatment to restore/maintain sinus rhythm. In currently commonly occurring diseases like hypertension and heart failure, atrial fibrillation could be a consequence of pathologically changed cell structure, increased neurohormonal activation and disturbed signal transduction among atrial (but also ventricular) cells [38]. Due to the beneficial effect of the drug blocking RAA system on diseases which are risk factors for atrial fibrillation (heart failure, hypertension, coronary artery disease) one may assume that the application of this type of drugs will decrease the risk of cardiac arrhythmias. In atrial fibrillation there are three types of remodeling: neurohormonal, electrical and structural. The potential mechanisms of the drug blocking RAA system protective effect include: the inhibition of structural remodeling by improving left ventricle and atrium hemodynamic parameters, decrease of atrial tension, inhibition of fibrosis, prevention of neurohormonal remodeling and a direct effect on ion channels (electrical remodeling) [39]. During fibrillation, atrial stretching with walls tension increases the local synthesis of the ANG II. The density of the AT receptors in atria is higher than in ventricles, therefore atria are more sensitive to the ANG II. Receptor stimulation causes the activation of mitogen activated protein kinase (MAP kinase) which in turn leads to the hypertrophy of myocytes, proliferation of fibroblasts and apoptosis [40]. Besides the structural remodeling, it was shown in experimental research [41] that the ANG II affects atrial "functional" remodeling, called electrical remodeling [41]. This pathophysiological process leads to significant disturbances. Thanks to protein kinase $\mathrm{C}$ activation and the phosphorylation of $\mathrm{L}$ channels, the calcium current through them is increased [42].

The beneficial effects of the ACE-I derive mainly from the inhibition of the ANG II synthesis, which directly causes the decrease of blood pressure, increase of large vessels compliance, decrease of hypertrophia and prevention of left ventricle remodeling. It is contributed by afterload and systolic tension reduction as well as the decrease of atrial pressure and tension which consequently lead the mitral insufficiency degree decrease. As regards neurohormonal re-adaptation, the concentration of catecholamines in blood and myocardium is diminished. The ACE-I application in patients with fixed atrial fibrillation decreases the expression and concentration of protein kinases, responsible for fibrosis activation [40]. It was shown in the experimental model of heart failure that enalapril inhibits both atrial fibrosis and remodeling. Consequently, the risk of atrial fibrillation as a complication of heart failure is also diminished. These data prove an important role of the RAA system in atrial remodeling [43].

Coming from bench to bedside, the prevention of the atrial fibrillation efficiency after the ACE-I was estimated retrospectively and prospectively. The retrospective analysis, concerning a group of hypertensive patients treated with the ACE-I or calcium antagonists showed significantly less atrial fibril- 
lation attacks in the ACE-I group [44]. In the retrospective analysis of the SOLVD trial, in which significant benefits from enalapril treatment were proven in patients with heart failure, the reduction of frequency of atrial fibrillation occurrence by $18.6 \%$ was stated in the group treated with the ACE-I, comparing to placebo [45]. Further reports from the trial pointed to a much smaller number of hospitalizations due to atrial tachyarrhythmias during enalapril treatment [46].

Prospective trails are not finished yet; they concern also the evaluation of drugs from the ARB group (GISSI-AF, ACTIVE-AF, ANTIPAF).

Another important issue is the pharmacological maintenance of sinus rhythm after a successful electrical cardioversion. Concerning also this secondary prevention, the retrospective analysis of results showed the decrease in the number of new atrial fibrillation attacks, in the group of patients treated with the ACE-I due to heart failure [47]. In the prospective trial the effects of associated amiodarone and enalapril treatment were compared to amiodarone alone, 28 days before planned cardioversion and after sinus thythm restoration. Combined treatment (by classical antiarrhythmic drug and the ACE-I) is burdened with smaller risk of cardiac rhythm disturbances both in the early and late periods of observation [48]. In another prospective trial [49] patients with paroxysmal atrial fibrillation were randomly assigned to 3 groups with following schemes of treatment: monotherapy (amiodarone), two-drug therapy (amiodarone and losartan), and three-drug therapy (amiodarone, perindopril and losartan). In groups subjected to combined treatment, a significantly smaller number of atrial fibrillation episodes was shown in short- and long-term observation ( $\mathrm{p}<0.006$ and $\mathrm{p}<0.04$ ). Moreover, in these groups a decrease of left atrium dimensions ( $p<0.001)$, making up the determinant of re-adaptation counterbalancing structural remodeling, was found. Importantly, there were no significant differences between groups treated with amiodarone and losartan and treated with amiodarone, losartan and perindopril [49].

Taking into consideration the long-term prophylaxis of atrial fibrillation, and simultaneously knowing the limited efficiency and potential adverse effects of antiarrhythmic drugs from groups I, III and IV, one can regard the ACE-I or the ARB as some of elements or even basis of pharmacotherapy. Therapy with these drugs is directed for the elimination of substrates of arrhythmias, burdened with a low risk of adverse effects and improves cardiovascular prognosis in a broad aspect. The powerful action of the ARB is distinctly shown by the newest experimental research in Marfan's syndrome. In the therapy of this disease, conditioned by the genetic mutation, losartan effectively inhibited the dilation of aorta. This observation was appreciated by a publication in Science [50] and the use of losartan in patients with Marfan's syndrome has been suggested.

\section{SUMMARY}

The ACE-I and ARB revealed several beneficial effects (cardioprotection, vasoprotection, cerebroprotection, nephroprotection), which creates the possibilities of choosing a suitable drug and, thanks to its special properties, adjusting the therapy to the target vessel bed (e.g. coronary, cerebral). Next, in some clinical situations the dual blockade may turn out to be the best solution as a remedy against the escape from the RAA system single blockade. One should pay attention to the increasing importance of sartans as hypotensive drugs. They show several beneficial features, such as effects on early hypertensive organ complications, a fast regression of organ changes and leveling the effect on risk factors in patients from a cardiovascular high risk group. With special interest, the results from the ONTARGET study, designed on a large population of patients, are expected. In this trial the effect of the dual blockade (ramipril and telmisartan) on the reduction of the occurrence of myocardial infarction, cerebral stroke and heart failure episodes, will be assessed.

\section{REFERENCES}

1. Dahlof B, Devereux RB, Kjeldsen SE, et al. LIFE Study Group. Cardiovascular morbidity and mortality in the Losartan Intervention ForEndpoint reduction in hypertension study (LIFE): a randomised trial against atenolol. Lancet. 2002; 359: 9951003.

2. Papademetriou V, Farsang C, Elmfeldt D, et al. Study on Cognition and Prognosis in the Elderly study group. Stroke prevention with the angiotensin II type 1-receptor blocker candesartan in elderly patients with isolated systolic hypertension: the Study on Cognition and Prognosis in the Elderly (SCOPE). J Am Coll Cardiol. 2004; 44: $1175-1180$

3. Schrader J, Luders S, Kulschewski A, et al. MOSES Study Group. Morbidity and Mortality After Stroke, Eprosartan Compared with Nitrendipine for Secondary Prevention: principal results of a prospective randomized controlled study (MOSES). Stroke. 2005; 36: 1218-1226.

4. Carlberg B, Samuelsson 0, Lindholm LH. Atenolol in hypertension: is it a wise choice? Lancet. 2004; 364: 1684-1689.

5. The PROGRESS Collaborative Group: randomised trial of a perindopril-based bloodpressure-lowering regimen among 6105 individuals with previous stroke or transient ischaemic attack. Lancet. 2001; 358: 1033-1041.

6. The PATS Collaborating Group: Post-stroke Antihypertensive Treatment Study. Chinese Med J. 1995; 108: 710-717.

7. ALLHAT Officers and Coordinators for the ALLHAT Collaborative Research Group: Major outcomes in high-risk hypertensive patients randomized to angiotensin-converting enzyme inhibitor or calcium channel blocker vs diuretic: the Antihypertensive and Lipid-Lowering Treatment to Prevent Heart Attack Trial (ALLHAT). JAMA. 2002; 288: 2981-2997.

8. Verdecchia P, Reboldi G, Angeli F, et al. Angiotensin-converting enzyme inhibitors and calcium channel blockers for coronary heart disease and stroke prevention. Hypertension. 2005; 46: 386-392.

9. Fournier A, Messerli FH, Achard JM, et al. Cerebroprotection mediated by angiotensin II: a hypothesis supported by recent randomized clinical trials. J Am Coll Cardiol. 2004; 43: 1343-1347.

10. Messerli FH, Simbo M, Chiadika A. Stroke Prevention: Not all Antihypertensive Drugs are Created Equal. J Renin Angiotensin Aldosterone Syst. 2005; 6 (Suppl 1): S4-S7.

11. Szczepańska-Sadowska E. Układ reninia-angiotensyna-aldosteron. In: Januszewicz A, Januszewicz W, Szczepańska-Sadowska E, Sznajderman M, eds. Nadciśnienie tętnicze. Kraków, Medycyna Praktyczna, 2004: 193-209.

12. Szczepańska-Sadowska E. Fizjologiczne i patofizjologiczne znaczenie receptorów dla angiotensyny. In: Januszewicz A, Januszewicz W, Rużyłło W, eds. Antagoniści receptora angiotensyny II $\mathrm{w}$ leczeniu chorób układu sercowo-naczyniowego. Kraków, Medycyna Praktyczna, 2006: 57-73.

13. Levy BI. Can angiotensin II type 2 receptors have deleterious effects in cardiovascular disease? Implications for therapeutic blockade of the renin-angiotensin system. Circulation. 2004; 109: 8-13.

14. Unger T. The angiotensin type 2 receptor: variations on an enigmatic theme. $J$ Hypertens. 1999; 17: 1775-1786. 


\section{REVIEW ARTICLES}

15. Gainer JV, Morrow JD, Loucland A, et al. Effect of bradykinin-receptor blockade on the response to angiotensinconverting-enzyme inhibitor in normotensive and hypertensive subjects. N Engl J Med. 1998; 339: 1285-1292.

16. Schulz R, Heusch G. Angiotensin II type 1 receptors in cerebral ischaemia-reperfusion: initiation of inflammation. J Hypertens Suppl. 2006; 24: S123-S129.

17. Barone FC, Coatney RW, Chandra S, et al. Eprosartan reduces cardiac hypertrophy, protects heart and kidney, and prevents early mortality in severely hypertensive stroke-prone rats. Cardiovasc Res. 2001; 50: 525-537.

18. Rutkowski $B$, Tylicki L. Antagoniści receptora angiotensyny II- terapia skojarzona z inhibitorami konwertazy angiotensyny. In: Januszewicz A, Januszewicz W, Rużyłto W, eds. Antagoniści receptora angiotensyny II w leczeniu chorób układu sercowo-naczyniowego. Kraków, Medycyna Praktyczna, 2006: 333-346.

19. Biollaz J, Brunner HR, Gavras I, et al. Antihypertensive therapy with MK 421: angiotensin II-renin relationships to evaluate efficacy of converting enzyme blockade. Cardiovasc Pharmacol. 1982; 4: 966-972.

20. Roig $E$, Perez-Villa $F$, Morales $M$, et al. Clinical implications of increased plasma angiotensin II despite ACE inhibitor therapy in patients with congestive heart failure. Eur Heart J. 2000; 21: 53-57.

21. Daugherty A, Rateri DL, Lu H, et al. Hypercholesterolemia stimulates angiotensin peptide synthesis and contributes to atherosclerosis through the $\mathrm{AT}_{1 \mathrm{~A}}$ receptor Circulation. 2004; 110: 3849-3857.

22. Mogensen $\mathrm{CE}$, Neldam $\mathrm{S}$, Tikkanen I, et al. Randomised controlled trial of dual blockade of renin-angiotensin system inpatients with hypertension, microalbuminuria, and non-insulin dependent diabetes: the candesartan and lisinopril microalbuminuria (CALM) study. Br Med J. 2000; 321: 1440-1444.

23. Jacobsen $P$, Andersen $S$, Rossing $K$, et al. Dual blockade of the renin-angiotensin system versus maximal recommended dose of ACE inhibition in diabetic nephropathy. Kidney Int. 2003; 63: 1874-1880.

24. Tylicki L, Rutkowski P, Renke M, et al. Renoprotective effect of small doses of losartan and enalapril in patients with primary glomerulonephritis. Short-term observation. Am J Nephrol. 2002; 22: 356-362.

25. Kincaid-Smith P, Fairley K, Packham D. Randomized controlled crossover study of the effect on proteinuria and blood pressure of adding an angiotensin II receptor antagonist to an angiotensin converting enzyme inhibitor in normotensive patients with chronic renal disease and proteinuria. Nephrol Dial Transplant. 2002; 17: 597-601.

26. Nakao N, Yoshimura A, Morita $\mathrm{H}$, et al. Combination treatment of angiotensin-II re ceptor blocker and angiotensin-converting-enzyme inhibitor in non-diabetic renal disease (COOPERATE): a randomised controlled trial. Lancet. 2003; 361: 117-124.

27. Gaciong Z. New therapeutic options in renal diseases - hypotensive therapy. Pol Arch Med Wewn. 2004; 112: 57-63.

28. Świtalski M. ACE and $A T_{1}$ inhibitors in used in the progression of chronic renal failure. Pol Arch Med Wewn. 2002; 107: 379-387.

29. Cohn JN, Tognoni G; Valsartan Heart Failure Trial Investigators. A randomized trial of the angiotensin-receptor blocker valsartan in chronic heart failure. N Engl J Med. 2001; 345: 1667-1675.

30. McMurray JJ, Ostergren J, Swedberg K, et al. CHARM Investigators and Committees. Effects of candesartan in patients with chronic heart failure and reduced left-ventricular systolic function taking angiotensin-converting-enzyme inhibitors: the CHARM-Added trial. Lancet. 2003; 362: 767-771.

31. Roik M, Starczewska MH, Stawicki S, et al. Effect of the optimal neurohormonal blockade on long-term survival in patients with chronic heart failure. Pol Arch Med Wewn. 2006; 115: 321-328.

32. Struthers AD. Angiotensin blockade or aldosterone blockade as the third neuroendocrineblocking drug in mild but symptomatic heart failure patients. Heart 2006; 92: 1728-1731.

33. Małecki R, Świtalski M, Małecka $L$, et al. Heart failure in advanced age. Pol Arch Med Wewn. 2004; 112: 125-138.

34. Kasma S, Toyama T, Hatori T, et al. Comparative effects of valsartan and enalapril on cardiac sympathetic nerve activity and plasma brain natriuretic peptide in patients with congestive heart failure. Heart. 2006; 92: 625-630.

35. Brown MJ. Renin: friend or foe? Heart. 2007 May 8; [Epub ahead of print].

36. Olsen $\mathrm{MH}$, Fossum $\mathrm{E}$, Hoieggen $\mathrm{A}$, et al. Long-term treatment with losartan versus atenolol improves insulin sensitivity in hypertension: ICARUS, a LIFE substudy. J Hypertens. 2005; 23: 891-898.

37. Lindholm LH, Persson $M$, Alaupovic $P$, et al. Metabolic outcome during 1 year in newly detected hypertensives: results of the Antihypertensive Treatment and Lipid Profile in a North of Sweden Efficacy Evaluation (ALPINE study). J Hypertens. 2003; 21: 1563-1574.

38. Goette A, Lendeckel U, Klein HU. Signal transduction systems and atrial fibrillation. Cardiovasc Res. 2002; 54: 247-258.

39. Ehrlich JR, Hohnloser SH, Nattel S. Role of angiotensin system and effects of its inhibition in atrial fibrillation: clinical and experimental evidence. Eur Heart J. 2006; 27: 512-518.

40. Goette A, Staack T, Rocken C, et al. Increased expression of extracellular signalregulated kinase and angiotensin-converting enzyme in human atria during atria fibrillation. J Am Coll Cardiol. 2000; 35: 1669-1677.

41. Nakashima H, Kumagai $K$, Urata $H$, et al. Angiotensin II antagonist prevents electrical remodeling in atrial fibrillation. Circulation. 2000; 101: 2612-2617.
42. Macrez N, Morel JL, Kalkbrenner F, et al. A betagamma dimer derived from G13 transduces the angiotensin AT1 receptor signal to stimulation of $\mathrm{Ca} 2+$ channels in rat portal vein myocytes. J Biol Chem. 1997; 272: 23180-23185.

43. Shi Y, Li D, Tardif JC, et al. Enalapril effects on atrial remodeling and atrial fibrillation in experimental congestive heart failure. Cardiovasc Res. 2002; 54: 456-461.

44. L'Allier PL, Ducharme A, Keller PF, et al. Angiotensin-converting enzyme inhibition in hypertensive patients is associated with a reduction in the occurrence of atrial fibrillation. J Am Coll Cardiol. 2004; 44: 159-164.

45. Vermes E, Tardif JC, Bourassa MG, et al. Enalapril decreases the incidence of atrial fibrillation in patients with left ventricular dysfunction: insight from the Studies of Left Ventricular Dysfunction (SOLVD) trials. Circulation. 2003; 107: 2926-2931.

46. Alsheikh-Ali AA, Wang PJ, Rand W, et al. Enalapril treatment and hospitalization with atrial tachyarrhythmias in patients with left ventricular dysfunction. Am Heart J. 2004; 147: 1061-1065.

47. Murray KT, Rottman JN, Arbogast PG, et al. Inhibition of angiotensin II signaling and recurrence of atrial fibrillation in AFFIRM. Heart Rhythm. 2004; 1: 669-675.

48. Ueng KC, Tsai TP, Yu WC, et al. Use of enalapril to facilitate sinus rhythm maintenance after external cardioversion of long-standing persistent atrial fibrillation. Results of a prospective and controlled study. Eur Heart J. 2003; 24: 2090-2098.

49. Yin Y, Dalal D, Liu Z, et al. Prospective randomized study comparing amiodarone vs amiodarone plus losartan vs. amiodarone plus perindopril for the prevention of atrial fibrillation recurrence in patients with lone paroxysmal atrial fibrillation. Eur Heart J. 2006; 27: 1841-1846.

50. Habashi JP, Judge DP, Holm TM, et al. Losartan, an $\mathrm{AT}_{1}$ antagonist, prevents aortic aneurysm in a mouse model of Marfan syndrome. Science. 2006; 312: 117-121. 